\title{
Comunicação Organizacional e Cooperativismo de Crédito: Análise das Centrais Sicoob de Minas Gerais
}

\section{Organizational Communication and Credit Cooperativism: Analysis of the Central's Sicoob of Minas Gerais}

Guilherme Luis Rosa da Silva guillerme.luis@ufv.br Graduando em Cooperativismo pela Universidade Federal de Viçosa (UFV). Bolsista de Iniciação Científica (Pibic/CNPq)

Ivonete da Silva Lopes

ivonetelopes@ufv.br

Doutora em Comunicação pela Universidade Federal Fluminense (UFF). Professora do Departamento de Economia Federal de Viçosa (UFV) 


\title{
RESUMO
}

Este artigo analisa as estratégias de comunicação organizacional adotadas pelas duas centrais mineiras do Sistema de Cooperativas de Crédito no Brasil (Sicoob). O objetivo é compreender a concepção de comunicação dessas organizações e relacionar os princípios do cooperativismo às práxis comunicativas. Como resultado, observa-se a importância da comunicação no planejamento estratégico das centrais. No entanto pode ser constatado também que as ações, que visam à inserção mercadológica, têm sido privilegiadas no cooperativismo de crédito em detrimento à educação cooperativista e ao interesse pela comunidade.

Palavras-chave: Cooperativismo de Crédito; Comunicação Organizacional; Sicoob.

\begin{abstract}
This article analyzes the organizational communication strategies adopted by the two credit central of the Sistema de Cooperativas de Crédito no Brasil (Sicoob) [System of Credit Cooperatives in Brazil] . The objective was to understand the communication conception of these organizations and to relate the principles of cooperativism to communicative praxis. As a result, it is observed the relevance of communication in the strategic planning of these organizations, however the market insertion has been the emphasis of communication in credit cooperativism to the detriment of cooperative education and interest in the community.
\end{abstract}

Keywords: Credit Cooperativism; Organizational communication; Sicoob 


\section{Introdução}

A comunicação organizacional vem ganhando espaço como área estratégica dentro das mais distintas organizações (públicas, privadas ou do terceiro setor) e se consolidando como objeto de estudo. É a área que planeja, desenvolve e acompanha a comunicação "no interior das organizações e entre ela e seus públicos, buscando estratégias e soluções. Sua característica é tratar a comunicação de forma estratégica e planejada, visando criar relacionamentos com os diversos públicos [...]”(BRANDÃO, 2009, p.6).

No contexto contemporâneo, a comunicação organizacional não se restringe ao envio de mensagens e/ou unicamente à criação de canais de comunicação. Ela precisa ser compreendida como algo mais completo. Conforme França (2012, p, 9), como "um processo de troca, ação partilhada, prática concreta, interação - e não apenas um processo de transmissão de mensagens". Se pensada a comunicação organizacional no cooperativismo, os desafios são ainda maiores. Além da comunicação institucional para o posicionamento da imagem e da comunicação mercadológica para a inserção de produtos e serviços no mercado, nesses empreendimentos, há, ou deveria haver, a preocupação com a formação democrática e a educação cooperativista (MORAES, 2006).

Este trabalho analisa a comunicação no ramo do cooperativismo com o maior número de associados no Brasil: o de crédito. Optou-se por estudar o Sistema de Cooperativas de Crédito no Brasil (Sicoob), o maior sistema financeiro cooperativo do país e de Minas Gerais. O objetivo dessa pesquisa é conhecer as estratégias de comunicação adotadas pelas duas centrais de crédito do Sistema Sicoob no estado para compreender o que elas entendem por comunicação e qual a relevância que esse setor possui para a inserção mercadológica e a educação cooperativista.

Este artigo está estruturado em quatro tópicos, além da introdução e das considerações finais. $O$ primeiro apresenta uma breve revisão teórica sobre $o$ cooperativismo de crédito, aponta a relevância do Sistema de Cooperativas de Crédito no Brasil (Sicoob) dentro do sistema financeiro cooperativista e aborda a atuação do Sicoob em Minas Gerais. O segundo fala sobre a comunicação organizacional associada ao cooperativismo de crédito. O terceiro descreve a metodologia utilizada. Já o último tópico analisa os dados obtidos na pesquisa realizada junto às duas centrais de crédito. 


\section{Cooperativismo de Crédito no Brasil}

Há quase dois séculos, nascia, em Manchester, na Inglaterra, uma nova forma de organização econômica e social, colocando-se como um movimento contrário à exploração dos trabalhadores pelo sistema capitalista ${ }^{1}$. Enquanto no capital, o principal objetivo é o lucro, o cooperativismo pauta-se nas pessoas, o que significa priorizar o desenvolvimento social e a organização autogestionária. Desde 1844 até os dias atuais, apesar dos avanço do capitalismo e das novas formas de opressão do capital sobre o trabalho, o cooperativismo tenta se pautar pelos sete princípios ditados pela Aliança Cooperativa Internacional (ACI). São eles: adesão livre e voluntária; gestão democrática; participação econômica dos membros; autonomia e independência; educação, formação e informação; cooperação entre cooperativas e preocupação com a comunidade.

Ao comparar o cooperativismo com outras atividades econômicas, Meinen e Port (2012, p.29) enfatizam que “o cooperativismo, por sinal, é o único movimento socioeconômico do planeta que se desenvolve sob uma mesma orientação doutrinária, e assim é desde o seu surgimento na primeira metade do Século XIX, em Rochdale, na Inglaterra". No entanto é relevante destacar que o fato de haver uma doutrina não significa que ela seja seguida igualmente por todas as cooperativas. Da mesma forma, os sete princípios podem ter pesos diferentes, de acordo com o ramo de atuação ou dentro de cada setor.

No Brasil, a primeira cooperativa de crédito nasceu em 1902, no distrito de Linha Imperial, na cidade gaúcha de Nova Petrópolis. "Essa foi a primeira cooperativa de crédito da América Latina, a Caixa de Economia e Empréstimo Amstad [...] atual Sicredi Pioneira- RS” (MEINEN, PORT 2012, p.102).

Ao longo desses 115 anos, o cooperativismo de crédito tornou-se o ramo mais expressivo do cooperativismo nacional. Atualmente, são 7,8 milhões de associados em todo o país. "Juntos as quatro maiores cooperativas de crédito Sicredi, Unicredi, Sicoob e Confesol - têm hoje R\$126 bilhões em ativos" (GOULART, 2016) ${ }^{2}$. Dentro do sistema

\footnotetext{
${ }^{1}$ A partir da união de 28 tecelões, no ano de 1844, no bairro de Rochdale, em Manchester, deu-se início o cooperativismo com criação de uma pequena cooperativa de consumo. Nela, o lucro não era principal objetivo e sim as pessoas que a compunham. O empreendimento era marcado pela sua forma autogestionária e se consolidou como uma nova alternativa econômica e social, atendendo ao mercado, com valores e princípios, contrários aos do capitalismo.

${ }^{2}$ Disponível em:http://economia.estadao.com.br/noticias/geral,cooperativas-de-credito-ja-sao-o-6-maiorbanco-do-pais, 10000024641
} 
financeiro cooperativo, o Sistema de Cooperativas de Crédito do Brasil (Sicoob) aparece como a maior instituição. Reúne cerca de $40 \%$ do total de integrantes das cooperativas de crédito brasileiras.

Assim como no Brasil, em Minas Gerais, esse ramo do cooperativismo possui o maior quadro social entre todos os demais. Conforme dados apresentados pelo Sistema OCEMG (2015), cerca de $80 \%$ dos cooperados, que o estado possui, estão vinculados a instituições de crédito: são 930,5 mil em um universo de 1,2 milhão de pessoas. Essa rede é formada por 195 cooperativas e 705 postos de atendimento, distribuídos em 445 municípios, abrangendo, dessa forma, aproximadamente 52\% de Minas Gerais.

\section{Sicoob em Minas Gerais}

O Sistema de Cooperativas de Crédito no Brasil (Sicoob) é o maior sistema financeiro cooperativo e a sexta maior instituição financeira do país. Hoje em dia, atua em 25 estados e no Distrito Federal, contando com mais de 2,4 mil postos de atendimentos e 3,2 milhões de cooperados (SICOOB, 2015).

O estado de Minas Gerais possui o maior número de cooperados do sistema Sicoob: $35 \%$ do total. São Paulo tem $22 \%$ e Santa Catarina, $17 \%$. Os outros $26 \%$ se distribuem pelo restante do país atendido pela rede. Nos três estados citados, estão localizados $75 \%$ dos pontos de atendimento e $75 \%$ dos ativos totais administrados, o que mostra uma ligação direta entre o número de associados, rede de atendimento e volume de ativos (MEINEN; PORT, 2012).

Para o desenvolvimento de suas atividades, o Sicoob é dividido em três graus de atuação: no primeiro, encontram-se as cooperativas de crédito e seus respectivos postos de atendimentos cooperativos (PACs); no segundo, estão as centrais responsáveis pelo suporte e integração dos serviços das cooperativas singulares filiadas ao sistema; já no terceiro, fica a Confederação Nacional das Cooperativas do Sicoob Ltda, cujas funções são defender os interesses do sistema, promover a uniformização e supervisão das gestões financeira, operacional, tecnológica e regimental, em prol da marca Sicoob.

O funcionamento sistêmico do Sicoob envolve 15 cooperativas centrais no país, que atuam para articular a integração estadual e/ou regional das singulares ao sistema. Enquanto alguns estados contam com apenas uma central regional, a exemplo do Sicoob Norte, que atende a sete unidades da federação, em Minas Gerais atuam duas. São elas: 
1) Cooperativa Central de Crédito Rural de Minas Gerais (Crediminas) ${ }^{3}$ : é a central mais antiga do estado, em atividade desde 1988. Possui 81 sedes de cooperativas de crédito, 542 unidades de atendimento e 530 mil associados. Embora não esteja especificado no site ou em outros materiais de comunicação, o Crediminas é mais conhecido por sua inserção em pequenas cidades e pelo cooperativismo de crédito rural.

2) Central das Cooperativas de Economia e Crédito de Minas Gerais (Cecremge) ${ }^{4}$ : surgiu em 1994 e integra cooperativas de diversos segmentos econômicos: comercial, rural, empregados, profissionais liberais e livre admissão. Apesar de mais heterogênea, possui um número menor de cooperativas em relação à Crediminas: são 69 filiadas com 206 agências, que somam mais de 413 mil associados.

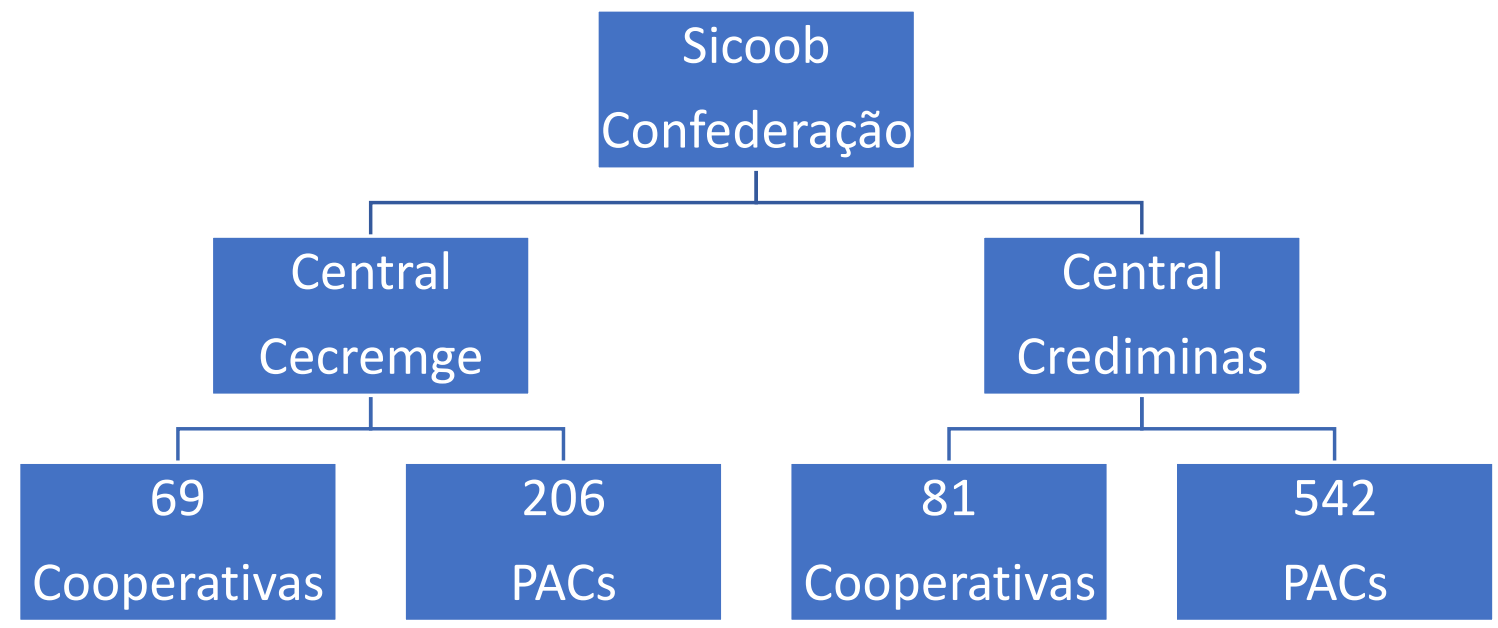

Figura 1 - O Sistema Sicoob.

Fonte: Elaboração própria, 2017

A Cecremge e Crediminas oferecem suporte aos processos operacionais, serviços prestados e representação às suas respectivas filiadas no intuito de integrar e alinhar suas diretrizes com o sistema financeiro nacional. Da mesma forma que as centrais, o setor de comunicação trabalha na perspectiva de padronizar os serviços e produtos oferecidos pela marca Sicoob.

\footnotetext{
${ }^{3}$ Disponível em: http://www.sicoobcrediminas.com.br/index.php/o-sicoob/sicoob-sistemacrediminas/sicoob-central-crediminas/

${ }^{4}$ Disponível em: http://www.sicoobcentralcecremge.com.br/quem-somos
} 


\section{Comunicação organizacional no sistema de cooperativas de crédito}

A comunicação tradicionalmente esteve vinculada ao processo de desenvolvimento socioeconômico. Pode ser considerada como uma prática necessária ao processo de democratização da sociedade, à promoção da cidadania, à popularização do conhecimento, à mobilização social e à contribuição ao fomento de atividades econômicas. "Pensada para o contexto cooperativista, a comunicação se mostra não só como uma ferramenta para estruturação da imagem e divulgação de um produto, mas principalmente como meio condutor da formação democrática” (MORAES, 2006, p.37).

Os produtos e serviços em comunicação contribuem para posicionar a organização; seja ela pública, privada ou do terceiro setor; na sociedade (KUNSCH, 2009; TORQUATO, 2012). A comunicação pode agregar valor às organizações, apoiar no cumprimento de sua missão, na fixação de seus valores e no desenvolvimento de ações para atingir suas metas. No entanto, no contexto contemporâneo, a comunicação organizacional não se reduz à criação de instrumentos de comunicação (sites, blogs, informativos ou perfil nas redes sociais). Ela possui um papel muito mais abrangente, que se refere a tudo que diz respeito à posição social e ao funcionamento da organização, desde o relacionamento com seus colaboradores até suas relações institucionais.

A partir de Moraes (2006); Kunsch (2009) e Torquato (2012), pode-se inferir que a comunicação organizacional no cooperativismo consegue auxiliar além da inserção da marca e do produto no mercado, atuando sobretudo no cumprimento dos princípios que orientam as instituições cooperativistas. Aqui, ressalta-se a relevância da comunicação especialmente no tocante a três princípios: 1) Gestão democrática: aspecto que pode ser um aliado para incentivar os associados a participar mais das atividades, dando, dessa forma, maior transparência à gestão; 2) Educação, formação e informação: garante aos associados o direito à informação e articula a comunicação na formação cooperativista; 3) Preocupação com comunidade: adoção de práticas para comunicar-se com a população da comunidade onde a organização está inserida e difusão da relevância do cooperativismo para o desenvolvimento local.

Para obter melhores resultados, conforme Cardoso (2003, p.1132), a comunicação organizacional " necessita ser entendida, de maneira integral, como elemento que atravessa todas as ações de uma empresa ou organização e que configura, de forma permanente, a construção de sua cultura e identidade". Por comunicação integrada entende-se: 
a junção da comunicação institucional, da comunicação mercadológica e da comunicação interna, que formam o composto da comunicação organizacional. [...] A soma de todas as atividades redundará na eficácia da comunicação nas organizações (KUNSCH,1997, p.115).

Empregar a comunicação integrada significa trabalhar a comunicação sob diferentes perspectivas, conforme apresentado por Toro e Werneck (2004) , : 1) comunicação de massa: voltada para o conjunto de pessoas da sociedade; 2) comunicação segmentada: integra ações desenvolvidas para atender às especificidade de cada públicoestratégico (colaboradores, associados, comunidade, apoiadores, entre outros); e 3) comunicação direta: contato personalizado, geralmente do tipo face a face, que inclui atendimento e/ou interação pela internet, debates, relações com o público interno, audiências públicas, reuniões, apresentações, grupos de trabalho e fóruns.

Ao se pensar em comunicação nas cooperativas, faz-se necessária uma análise do público desse ambiente, visto a relação de dono-usuário dos associados desse tipo de organização. Diante dessa especificidade, o trabalho da comunicação, em tais instituições, requer estratégias próprias para o seu desenvolvimento, de modo que as interações do meio e o fluxo de informações atendam à necessidade tanto do gerenciamento das cooperativas quanto dos cooperados. Na concepção de Souza et al (2014, p.497), a comunicação pode contribuir para melhorar a administração, no entanto "apresenta desafios específicos quanto às técnicas utilizadas, sobretudo para evitar o surgimento de barreiras que impeçam o desenvolvimento de fluxos de informação entre os públicos envolvidos no empreendimento cooperativo".

As dificuldades citadas por Sousa et al (2014) podem ocorrer quando não se leva em conta principalmente a cultura da organização. Fisher (1993,p.4), citado por Amorim (2006, p.77), tem visão semelhante “ [a comunicação organizacional] é um processo, dependente da cultura, de trocas de informações e criação de relacionamentos dentro de ambientes gerenciais, orientados por objetivos".

Em cooperativas, esse processo envolve o conhecimento sobre as características das comunidades onde estão inseridas e aspectos da educação cooperativa, tais como a doutrina, valores e princípios das respectivas organizações. Somente dessa forma, é possível desenvolver ações, que possibilitem a compreensão das atividades do empreendimento (FRANTZ, 1983). 
Sousa et.al (2014, p.497) corrobora essa versão ao enfatizar o papel da comunicação organizacional para a educação cooperativista e vice-versa:

[...] a educação cooperativista tem exatamente o papel de atuar simultaneamente na gestão social e empresarial das cooperativas, com o objetivo de promover melhorias tanto no que se refere ao aumento da participação dos cooperados, quanto na profissionalização da gestão, a fim de fortalecer a sua específica estrutura organizacional. Essa característica do processo comunicativo, por meio da educação cooperativista, pode ser utilizada na capacitação dos sócios, promovendo a participação dialógica e educativa e a busca de equilíbrio entre os interesses dos públicos envolvidos.

A comunicação desenvolvida no âmbito do cooperativismo possui as funções de colaborar para a educação cooperativista e estimular a participação dos cooperados, além da tradicional de melhorar a imagem, o posicionamento e o relacionamento com a sociedade. Adiciona-se ainda o papel de dar transparência e promover uma gestão mais democrática.

\section{Metodologia}

O percurso metodológico deste trabalho consistiu em pesquisa bibliográfica em artigos, tese, além de livros da área de comunicação organizacional e comunicação em cooperativa, com destaque para os autores Kunsch (2009); Moraes (2006) e Toro e Werneck (2004), Souza el.al (2014). Na pesquisa de campo, com o intuito de coletar informações sobre o funcionamento dos setores de comunicação ${ }^{5}$, foram realizadas duas entrevistas, em fevereiro de 2017, com os gestores da área de comunicação das centrais do sistema Sicoob no estado de Minas Gerais. Os dados foram coletados presencialmente a partir de um roteiro semiestruturado.

Esta pesquisa é de caráter exploratório, ou seja, busca trazer mais informações sobre um determinado assunto do qual não se possui muito conhecimento, conforme descreve Andrade (2010). Desse modo, a pesquisa exploratória objetiva trazer novas discussões e estimular o desenvolvimento de outros trabalhos, neste caso, referentes à comunicação organizacional em cooperativas, tema ainda pouco debatido no ambiente acadêmico.

\footnotetext{
${ }^{5}$ As centrais, a partir da análise, passam a ser identificadas pelas letras A e B para assegurar o anonimato.
} 


\section{Análise de dados: Comunicação nas Centrais de Crédito do Sicoob em Minas Gerais}

Em uma organização composta por confederação, centrais e singulares; o processo de comunicação busca articular os interesses de todos os níveis e dar transparência à gestão. Em um sistema financeiro cooperativo, tais informações são de suma importância para manter uma boa relação entre a cooperativa e seus usuários.

Atuar sob a bandeira Sicoob significa oferecer produtos e serviços padronizados, além de ter políticas e estratégias comuns de comunicação e marketing (SICOOB,2017). A normatização favorece o uso da marca, porém pode dificultar na adequação da linguagem e imagens para a comunicação direcionada. O cooperativismo de crédito envolve públicos bastante segmentados. Além das cooperativas de livre admissão, existem aquelas que atuam com os mais diversos setores econômicos, o que deveria desencadear diferentes formas de abordagem com os cooperados e as comunidades onde estas organizações estão inseridas.

Nesta seção, o objetivo é analisar a comunicação organizacional das centrais do sistema Sicoob em Minas Gerais a partir da estrutura do setor. Cabe destacar que, dentro da organização do referido sistema, as centrais devem mediar e/ou articular o relacionamento entre a confederação, as cooperativas filiadas e seus respectivos cooperados. Dessa forma, existe a necessidade de se manter um setor responsável pela interlocução entre as organizações e seus públicos.

Abaixo está descrita a estrutura do setor de comunicação das duas centrais mineiras:

1) Central A - conta com uma gerência de comunicação e marketing responsável pelo suporte das demandas internas e pela assistência às suas cooperativas filiadas. A equipe possui um gerente, analistas nas áreas de comunicação social e marketing e um assistente de comunicação. A gerência é encarregada de traçar estratégias baseadas no plano realizada pela confederação e repassar as campanhas e peças nacionais às cooperativas. O setor atua fornecendo suporte às afiliadas, uma espécie de consultoria: "nosso trabalho é muito em consonância com a gerência de negócios, porque é muita campanha de produtos, campanha para o associado. Nosso trabalho é complementar o deles [gerência de negócios]" (Entrevistado 1). O setor dá ainda apoio aos eventos realizados; cria peças, hotsite e outros materiais de comunicação visual; faz as coberturas jornalística e fotográfica dos eventos; além de realizar outras funções de divulgação. De acordo com o Entrevistado 1, devido à relevância estratégica da área de comunicação, a gerência está 
diretamente ligada ao presidente da central, o que agiliza o processo de tomada de decisão

2) Central B - há dois anos, o setor de comunicação integra a gerência de negócios, mas, anteriormente, ocupava o status de gerência. A mudança ocorreu porque a comunicação deixou de ser entendida apenas como "institucional" e passou a ser vista como "mercadológica" (Entrevistado 2). A estrutura atual conta com profissionais da área de comunicação social, relações públicas e marketing. As atividades são divididas em três frentes: comunicação institucional, comunicação mercadológica e comunicação interna, contemplando, assim, o modelo da comunicação integrada apresentada por Kunsch(1997). A equipe desenvolve treinamentos e dá suporte para a gestão, adequação e alinhamento em campanhas e ações mercadológicas de marketing e comunicação. Para facilitar a comunicação com as cooperativas, a central possui uma pessoa responsável em cada filiada. Ela é encarregada de fazer a interface com a central no que tange às atividades do setor.

Apesar de as duas centrais contarem com equipes específicas para a comunicação, as estruturas ocupam posições diferentes dentro do organograma. Enquanto na primeira, possui status de uma gerência vinculada diretamente à presidência, na segunda, a comunicação é um dos setores da gerência de negócios. Do ponto de vista organizacional, a situação pode indicar que a comunicação possui uma concepção mais ampla dentro da Central A por estar diretamente ligada à presidência, o que tende a facilitar a tomada de decisões com mais agilidade e dar maior dinamismo ao processo de comunicação. A ligação da comunicação à gerência de negócios dá a entender que a comunicação mercadológica é mais valorizada em relação às demais áreas.

Outro aspecto relevante é o fato da atuação de os setores de comunicação dessas centrais atuarem em sintonia com o planejamento nacional realizado pela confederação. Desse modo, o trabalho da central concentra-se no esforço de direcionar e alinhar a comunicação das cooperativas singulares às diretrizes estabelecidas pelo plano nacional, além de oferecer suporte às filiadas, especialmente àquelas que não possuem um setor de comunicação.

\section{A relevância e os canais de comunicação}

Para análise deste tópico, os entrevistados responderam um questionário com base em uma escala, onde 5 representa "muito importante" e 1, "pouca relevância". 
Quadro 1: Relevância da comunicação

\begin{tabular}{|l|l|l|}
\hline & $\begin{array}{l}\text { Entrevistado } \\
\text { 1 Central A }\end{array}$ & $\begin{array}{c}\text { Entrevistado } \\
\text { 2 Central B }\end{array}$ \\
\hline 1.Captar novas cooperativas & 5 & 2 \\
\hline 2. Dialogar com as cooperativas & 5 & 5 \\
\hline 3.Mostrar transparência da gestão & 5 & 5 \\
\hline 4. Promover educação cooperativista & 1 & 5 \\
\hline $\begin{array}{l}\text { 5. Divulgar os valores do } \\
\text { cooperativismo para a sociedade }\end{array}$ & 5 & 5 \\
\hline $\begin{array}{l}\text { 6.Realização de um plano de } \\
\text { comunicação }\end{array}$ & 5 & 5 \\
\hline $\begin{array}{l}\text { 7.Intercooperação ( Apoio e troca de } \\
\text { informações com outras cooperativas) }\end{array}$ & 5 & 5 \\
\hline $\begin{array}{l}\text { 8.Realização de assembleias } \\
\text { (extraordinárias e ordinárias) }\end{array}$ & 5 & 5 \\
\hline
\end{tabular}

Fonte: Elaboração própria, 2017.

Os resultados obtidos para cada ponto estão descritos a seguir:

1.Captar novas cooperativas: de acordo com Entrevistado 1, que optou pela nota 5, as atividades de comunicação têm como uma de suas funções prospectar novas cooperativas a fim de aumentar seu quadro social, ou seja, formalizar novas cooperativas crédito para serem filiadas ao sistema. Na central B, onde a nota dada foi 2, o setor de comunicação não pauta seus esforços para concretização desse objetivo, pois suas atividades são direcionadas ao suporte das cooperativas filiadas (Entrevistado 2).

2.Dialogar com as cooperativas: ambos marcaram a opção 5. Conforme o Entrevistado 1, as ações de comunicação da central buscam ajudar no desenvolvimento das cooperativas filiadas ao sistema, consideradas o público-alvo do empreendimento.

3.Mostrar transparência da gestão: novamente, responderam a opção 5. A transparência na gestão, segundo o Entrevistado 2, “é um dos valores da central”, uma vez que os cooperados necessitam de constantes informações sobre o andamento financeiro próprio e o da cooperativa.

4.Promover educação cooperativista: de acordo com o Entrevistado 2, que atribui nota 5 a esse critério, um dos esforços importantes no trabalho da comunicação é a promoção da 
educação aos seus cooperados, o que corrobora o pensamento de Souza et. Al (2014), Frantz(1983). Já o Entrevistado 1 marcou a opção 1, pelo fato de a educação cooperativista ser trabalhada por outro setor da central: a gerência de recursos humanos, que realiza cursos e treinamentos aos diretores e cooperados de suas filiais.

5.Divulgar os valores do cooperativismo para a sociedade: os dois participantes indicaram a opção 5. Para o Entrevistado 1, a divulgação é uma forma de demonstrar os princípios, valores, missão e visão que norteiam a Central A. Já de acordo com o Entrevistado 2, ela é vista como foco das campanhas institucionais da Central B. Pelo resultado obtido nesse item, é possível concluir que os trabalhos das centrais, no que tange à divulgação dos valores do cooperativismo nas comunidades, reforçam a tese apresentada por Frantz (1983).

6.Realização de um plano de comunicação: ambos deram nota 5. Os entrevistados salientaram que disseminam às filiadas as diretrizes e o planejamento nacional de comunicação e marketing do Sicoob Confederação. Dessa forma, é possível alinhar as atividades e o calendário de campanhas e eventos realizados ao longo do ano.

7.Intercooperação: a opção 5 foi novamente escolhida pelos dois participantes. Conforme o Entrevistado 1, “o que a gente mais preza, inclusive de uma cooperativa ser harmoniosa com a outra, fazer a intercooperação com a outra, não enxergar a outra cooperativa como concorrente". Esse item é trabalhado por meio de treinamentos, eventos e reuniões, que possibilitam o encontro de representantes de diferentes cooperativas.

8.Realização de assembleias (ordinárias e extraordinárias): ambos marcaram 5. Na Central A, segundo o Entrevistado 1, a comunicação é responsável pela divulgação e elaboração do relatório de gestão, que é entregue aos cooperados nos dias da assembleia. $\mathrm{Na}$ Central B, o Entrevistado 2 destacou que o setor trabalha para tentar aumentar a participação dos cooperados nesses encontros, o que é tido como um grande desafio. Nesse sentido, canaliza esforços, em seus meios de divulgação, para buscar mais mobilização entre os associados.

\section{Canais de comunicação}

As cooperativas são o público-alvo do setor de comunicação das centrais. No entanto a comunidade no geral também é atingida pelas ações, como o patrocínio ao Campeonato Mineiro de Futebol realizado em 2017, campanhas em outdoors e anúncios em rádios nacionais e estaduais. 
Quadro 1: Principais canais de comunicação

\begin{tabular}{|l|l|l|l|l|}
\hline Central & Boletim & Rede Social & Jornal & $\begin{array}{l}\text { Comunicação } \\
\text { Interna }\end{array}$ \\
\hline Central A & $\begin{array}{l}\text { De acordo com a } \\
\text { demanda }\end{array}$ & $\begin{array}{l}\text { Redireciona para } \\
\text { Facebook e } \\
\text { YouTube Sicoob } \\
\text { oficial da } \\
\text { confederação }\end{array}$ & Trimestral & Intranet \\
\hline Central B & Bi-semanal & $\begin{array}{l}\text { Redireciona para } \\
\text { Facebook e } \\
\text { YouTube Sicoob } \\
\text { oficial da } \\
\text { confederação }\end{array}$ & Bimestral & $\begin{array}{l}\text { Intranet } \\
\text { Quadro } \\
\text { avisos }\end{array}$ \\
\hline
\end{tabular}

Fonte: Elaboração própria com base nas entrevista.2017.

As estratégias harmoniosas de comunicação apresentadas por Toro e Werneck (2004) estão presentes nas duas centrais. Entre elas, podem ser destacadas a comunicação direta; realizada por meio de um programa de intranet, onde são trocadas informações cotidianas entre diretoria e colaboradores; e a comunicação segmentada, feita em boletins e jornais destinados às cooperativas filiadas dos respectivos sistemas.

Já as ações relativas à comunicação de massa, como o uso das redes e mídias sociais (Facebook e Youtube, por exemplo), não são gerenciadas pelas centrais, cabendo à confederação o papel de produzir conteúdo para as postagens. O entrevistado da Central A explica que opção foi baseada na "a questão do pensamento sistêmico, de falarmos a mesma língua fez com que direcionássemos para o Sicoob oficial. As cooperativas com página nessa rede social acabam replicando as informações do Sicoob" (Entrevistado 1).

$\mathrm{O}$ argumento do entrevistado permite levantar alguns questionamentos sobre o uso do Facebook nas cooperativas, que optam, na maioria das vezes, por simplesmente compartilhar informações da confederação. Chama atenção a necessidade de se ter um profissional para o monitoramento das redes sociais localmente, considerando que as páginas das coorporativas também são um canal de atendimento ao público. Se não houver diálogo (respostas para as questões postadas) e atualização frequente, talvez a 
melhor opção seja não utilizá-las ou adotar a estratégia de redirecioná-las para a página da confederação.

Para a comunicação mais frequente, as centrais utilizam boletins (newsletter) enviados por e-mail. Contudo observa-se uma diferença entre as duas centrais. $\mathrm{Na} \mathrm{B}$, o boletim é bi-semanal, sendo encaminhado no início da semana com informações motivacionais e, no fim de semana, focando em produtos, serviços e campanhas. Já na Central $\mathrm{B}$, não há periodicidade definida. O envio é de acordo com a demanda da organização.

Jornais bimestrais (Central A) e trimestrais (Central B) são utilizados como uma ferramenta mais elaborada de comunicação entre as centrais e suas singulares. Nos jornais, a ênfase dada é à capacitação e aos produtos e serviços oferecidos, pouco se falando sobre a educação cooperativista. Os conteúdos se concentram na divulgação de eventos, metas alcançadas, projeções e balancetes patrimoniais das respectivas centrais. No tocante à comunicação interna, percebem-se poucos esforços para desenvolver canais de comunicação com os colaboradores, ficando praticamente restrito à intranet.

Outro quesito que merece atenção é o patrocínio das duas centrais ao Campeonato Mineiro de Futebol 2017. O intuito foi dar maior visibilidade à marca Sicoob no estado por meio das placas publicitárias nos estádios de futebol e cobertura do evento esportivo por emissoras de rádio, sites de notícias e televisão.

\section{Considerações Finais}

Evidenciou-se, por meio das entrevistas, a relevância da comunicação nas centrais Sicoob de Minas Gerais. Esse setor atua na operacionalização das estratégias definidas pelo planejamento de comunicação do Sicoob Confederação assim como oferece suporte às cooperativas no alinhamento da comunicação e do marketing. $\mathrm{O}$ fato de existirem estruturas de comunicação formadas por profissionais especializados demonstra, de certo modo, a percepção sobre o papel estratégico da área para o cooperativismo de crédito mineiro.

As centrais trabalham como replicadoras das políticas nacionais de comunicação do Sicoob para as singulares, o que pode levar a inferir que existe pouca flexibilidade para adaptação da linguagem em um setor que atua com públicos bastante distintos: há cooperativas de livre admissão e por segmentação econômica (rural, de profissionais 
liberais e da saúde, por exemplo). Entre os cooperados, existem possíveis diferenças culturais, de escolaridade, de atividades profissionais, entre outras; o que precisa ser considerado para se pensar as estratégias de comunicação do cooperativismo de crédito. Entende-se, portanto, ser necessária a adequação da linguagem aos respectivos públicos.

Observou-se também que a comunicação é utilizada especialmente para promover a inserção mercadológica com a divulgação dos produtos e serviços das centrais em detrimento de outras funções, que poderiam existir no cooperativismo, tal como a contribuição para a educação cooperativista e para o desenvolvimento local. Esse trabalho poderia ser feito por meio de campanhas, eventos, cursos e treinamentos nas comunidades onde estão inseridas a fim de proporcionar o conhecimento sobre o cooperativismo e o funcionamento do sistema cooperativo financeiro.

\section{Referências bibliográficas}

AMORIM, A. L. M. Comunicação organizacional, processos decisório, vantagem competitiva e efetividade em duas cooperativas paranaenses de agronegócio. 2006. 246 f. Dissertação (Mestrado em Administração) - Setor de Ciências Sociais Aplicadas, Universidade Federal do Paraná, Curitiba, 2006.

ANDRADE, M. M. Introdução à metodologia do trabalho científico: elaboração de trabalhos na graduação. São Paulo, Ed. Atlas, 2010.

BRANDÃO.P.E. Conceito de comunicação pública. In: DUARTE,J (org). Comunicação Pública: Estado, Mercado, Sociedade e Interesse Público. São Paulo: Atlas, 2009. p.1-33

CARDOSO, O. Comunicação empresarial versus comunicação organizacional: novos desafios teóricos. Revista de Administração Pública (RAP). Rio de Janeiro v. 40, n.6, p.1123-1144, Nov./Dez.

FRANÇA, F. Públicos: como identificá-los em nova visão estratégica: business relationship. $3^{\text {a }}$. São Paulo: Ed.Yendis, 2012.

FRANTZ, W. Comunicação e educação em cooperativas: retrospectiva histórica e importância atual. Perspectiva Econômica. São Leopoldo, ano XVII, v. 13, nº 39, 1983.

GOULART, J. Cooperativas de Crédito já são o $6^{\circ}$ maior banco do país. O Estadão. Disponível em: http://economia.estadao.com.br/noticias/geral,cooperativas-de-credito-ja-sao-o6-maior-banco-do-pais,10000024641. Acesso em: 20 abr. 2016

KUNSCH, Margarida Maria Krohling. Planejamento de relações públicas na comunicação integrada. Summus editorial, 1997.

KUNSCH, M. (org). Comunicação organizacional: histórico, fundamentos e processos. V 1. São Paulo: Saraiva, 2009. 
MEINEN, E., PORT, M. O cooperativismo de crédito ontem, hoje e amanhã. Brasília. CONFEBRAS.2012.430p.

MORAES, S. R. Comunicação e Cooperativismo: uma outra comunicação é possível. Revista Inovcom. Vol. 1, No 1, p. 34-46 - Maio 2006 Vol. 1, No 1, p. 34-46 - Maio 2006

OCEMG. Anuário de informações econômicas e sócias do cooperativismo mineiro. Belo Horizonte, 2015. Disponível em:< http://www.minasgerais.coop.br/pagina/146/anuario-deinformacoes-economicas-e-sociais.aspx>. Acesso em 8 fev de 2017.

SICOOB. Modelo Organizacional. Disponível em: $<$ http://www.sicoob.com.br/o-sicoob-modeloorganizacional>. Acesso em $6 \mathrm{dez}$ de 2016

$$
\text { .Relatório Anual 2015. Disponível em: }
$$

<http://www.sicoob.com.br/documents/21826417/31143763/relatorio_sistemico2.pdf/60ce2b91

-75d1-4b08-85e1-dcf01def285b>. Acesso em: $10 \mathrm{fev}$ de 2017

SICOOB CENTRAL CECREMGE. Quem Somos. Disponível em: <http://www.sicoobcentralcecremge.com.br/quem-somos>. Acesso em 6 dez de 2016

SICOOB CENTRAL CREDIMANS. O Sicoob Central Crediminas. Disponível em:< http://www.sicoobcrediminas.com.br/index.php/o-sicoob/sicoob-sistema-crediminas/sicoobcentral-crediminas/>. Acesso em 7 dez de 2016

SOUZA, et. al. A comunicação na articulação agroindustrial entre uma cooperativa central, suas cooperativas singulares e cooperados. Revista de Economia e Sociologia Rural, São Paulo, n.3, set. 2014. Disponível em: < http://www.scielo.br/scielo.php?script=sci_arttext\&pid=S010320032014000300005 > . Acesso em: 2 dez de 2016.

TORO, José Bernardo; WERNECK, Nísia M. Duarte. Mobilização social: um modo de construir a cidadania e a participação. Belo Horizonte: Autêntica, 2004.

TORQUATO, G. Cultura, poder, comunicação, crise e imagem. Fundamentos das organizações do século XXI. São Paulo: Cengage Learning, 2012. 